\title{
Energy-saving wastewater treatment systems: formulation of cost functions
}

\author{
R. Nogueira*, I. Ferreira*, P. Janknecht** J.J. Rodríguez ${ }^{\star \star *}$, P. Oliveira**** and A.G. Brito* \\ *School of Engineering, Center of Biological Engineering, University of Minho, Campus de Gualtar, \\ 4710-057 Braga, Portugal (E-mail: regina@deb.uminho.pt; produtor.relva@clix.pt; agbrito@deb.uminho.pt) \\ ${ }^{\star *}$ Centro de las Nuevas Tecnologías del Agua, Avda. Américo Vespucio S/N. Ed. Cartuja, bloque B, Mod. \\ 10, 41092 Sevilla, España

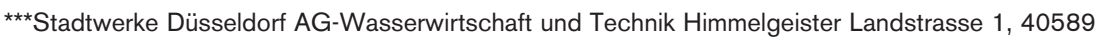 \\ Düsseldorf, Deutschland

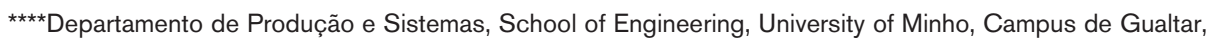 \\ 4710-057 Braga, Portugal
}

Abstract Natural interactions between water, soil, atmosphere, plants and microorganisms include physical, chemical and biological processes with decontaminating capacities. Natural or energy-saving wastewater treatment systems utilize these processes and thereby enable a sustainable management in the field of wastewater treatment, offering low investment and operation costs, little or no energy consumption, little and low-skill labor requirements, good landscape integration and excellent feasibility for small settlements, especially when remote from centralized sewer systems.

The objective of this work is the development of cost functions for investment and operation of energysaving wastewater treatment technologies. Cost functions are essential for making cost estimations based on a very reduced number of variables. The latter are easily identified and quantified and have a direct bearing on the costs in question. The formulated investment and operation cost functions follow a power law, and the costs decrease with the increase of the population served. The different energy-saving wastewater treatment systems serving small population settlements, between 50 p.e. and 250 p.e., present associated investment costs varying from $400 € /$ p.e. to $200 € /$ p.e. and annual operation costs in the range of $70 € /$ p.e. to $20 € /$ p.e., respectively.

Keywords Constructed wetland; cost function; slow rate infiltration; wastewater treatment

\section{Introduction}

The municipal wastewater directive 91/271/CE of the Council, from May 1991, relating to wastewater treatment required for small communities, constitutes a master framework in the environmental policy of European Union. One of the main dispositions of the directive establishes that communities, with less than 2000 inhabitants, discharging their effluents in freshwaters or estuaries are obliged to have an appropriate wastewater treatment whenever a sewer system is present.

Actually, the majority of wastewater collection and treatment systems that are built or in construction in the Atlantic Space refer to small rural communities geographically spread. Under these conditions it is not feasible, from an economical point of view, to centralize wastewater in a single system. The implementation of decentralized treatment solutions is assumed as a priority. A pertinent question arises then, relating to the selection of the most adequate treatment, considering two options, natural or energy-saving wastewater treatment systems versus intensive treatment systems.

In the environment, physical, chemical and biological processes result from the interaction between water, soil, plants, microorganisms, and the atmosphere. Both energy-saving treatment systems (Crites and Tchobanoglous, 1998) and intensive treatment systems (Metcalf and 
Eddy, Inc., 2003) are designed to take advantage of these processes to provide wastewater treatment. The processes involved in energy-saving systems include many of those used in intensive systems (e.g. adsorption, chemical precipitation, biological degradation) and others, unique to energy-saving systems, such as photosynthesis, photo-oxidation and plant uptake. Despite both treatment systems mimicking nature there are substantial differences: in energysaving systems, the processes take place at a natural rate and tend to occur simultaneously in a single tank, as opposed to the intensive treatment systems, where the processes occur sequentially in separate tanks and at accelerated rates, as a result of energy input.

The energy-saving technologies which nowadays are of great use to the wastewater treatment of small communities are those that make use of the soil as a means of infiltration (e.g. slow rate infiltration); simulate the conditions of natural wetlands (e.g. constructed wetlands) and the ones that simulate the natural processes of treatment which occur in rivers, lakes (e.g. lagoons) (García et al., 2006). The different wastewater treatments systems show different performances, result in different impacts to the environment and have different associated costs. It is of major importance in the selection of the type of system and on its project the issue of the costs involved, not only the initial cost of construction but also the cost of annual operation. Cost functions are essential to make cost estimations based on a very reduced number of variables. The latter are easily identified and quantified and have a direct bearing on the costs in question. This tool enables a first selection, based on costs, between the different wastewater treatment solutions for small communities.

The objective of this work is the development of cost functions for investment and operation of energy-saving wastewater treatment technologies. The work was developed under the DEPURANAT project - Sustainable management of wastewater in rural area, financed by the Program INTEREG III-B Atlantic Space, having started in 2004, with an expected duration of 3 years. The project is intended to support the implementation of energy-saving wastewater treatment systems in rural and natural areas of the Atlantic Space.

\section{Materials and methods}

The formulation of cost functions for energy-saving wastewater treatment systems for small communities (lower than 250 p.e. (Population equivalent (p.e.) - biodegradable organic load presenting a 5 day biochemcal oxygen demand of $60 \mathrm{~g}$ of oxygen per day)) followed a phased methodology.

Initially, an inventory of costs was complied consisting on the collection of economical data from the treatment systems constructed or upgraded under the DEPURANAT project. Two types of costs were contemplated: investment costs and operation costs (maintenance + exploitation). The enquiry elaborated for this purpose (Figure 1) was distributed, for fulfillment, to the partners, located in the Canary Islands (Spain), Andalusia (Spain) and Minho (Portugal). The treatment systems belonging to the project included the following treatment steps:

- Pre-treatment - screening

- Primary Treatment - septic tank or Imhoff tank

- Secondary treatment:

- Vertical-flow constructed wetland (VFCW)

- Horizontal-flow constructed wetland (HFCW)

- Free-water-surface constructed wetland (FWFCW)

- Combination series/parallel of constructed wetlands

- Slow rate infiltration (SRI)

Later on, aiming at the collection of some missing data and the validation of the remainder, a visit to all treatment systems was performed, through which was possible the gathering of all the project coordinators, the responsible for the operation of each treatment system, as well as, the project architect of the new constructed systems. 


\begin{tabular}{|c|c|c|c|c|c|c|c|c|c|}
\hline \multicolumn{10}{|c|}{$\begin{array}{c}\text { COSTS ENQUIRY } \\
\text { ENERGY-SAVING WASTEWATER TREATMENT SYSTEMS }\end{array}$} \\
\hline & $\begin{array}{l}\text { Nomination: } \\
\text { Location: } \\
\text { Type of wastewater: }\end{array}$ & & & & & $\begin{array}{l}\text { Served Population (p.e.): } \\
\text { Flow rate }\left(\mathrm{m}^{3} / \mathrm{d}\right) \text { : } \\
\text { Total occupied area }\left(\mathrm{m}^{2}\right) \text { : }\end{array}$ & & & \\
\hline & Investment cost & 咅 & $\overline{5}$ & 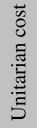 & & Operation cost & 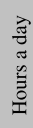 & 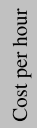 & 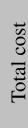 \\
\hline $\begin{array}{l}1 \\
1.1 \\
1.2 \\
1.3 \\
1.4 \\
1.5 \\
1.6 \\
1.7 \\
1.8 \\
1.9 \\
1.10 \\
\\
2 \\
2.1 \\
2.2\end{array}$ & $\begin{array}{l}\text { CONSTRUCTION COST } \\
\text { Land } \\
\text { Land excavation } \\
\text { Containment } \\
\text { Drainage } \\
\text { Tubes and accessories } \\
\text { Proofing } \\
\text { Fence } \\
\text { Medium } \\
\text { Biomass } \\
\text { Others } \\
\text { EQUIPMENT COST } \\
\text { Pump } \\
\text { Flowmeter }\end{array}$ & & & & $\begin{array}{l}1 \\
1.1 \\
1.2 \\
1.3 \\
1.4 \\
1.5 \\
1.6 \\
\\
2 \\
2.1 \\
2.2 \\
2.3 \\
2.4 \\
2.5 \\
2.6 \\
\\
3 \\
3.1 \\
3.2 \\
3.3 \\
3.4 \\
3.5\end{array}$ & $\begin{array}{l}\text { NORMAL MAINTENANCE COST } \\
\text { Valves maintenance } \\
\text { Control of hydraulic functioning } \\
\text { Control of floatings } \\
\text { Control of water color } \\
\text { Control of register notebook } \\
\text { Others } \\
\text { REGULAR MAINTENANCE COST }{ }^{2} \\
\text { Floating extraction } \\
\text { Regulation of water levels } \\
\text { Control of discharges quality } \\
\text { Cleaning of borders/involving space } \\
\text { New plantation } \\
\text { Others } \\
\text { EXCEPTIONAL MAINTENANCE COST } \\
\text { Biomass cut } \\
\text { Pruning } \\
\text { Docks cleaning } \\
\text { Cleaning of treatment residues } \\
\text { Others }\end{array}$ & & & \\
\hline
\end{tabular}

Figure 1 Enquire of costs of energy-saving wastewater treatment systems constructed or upgraded under DEPURANAT project

Finally, after data validation, the assessment of investment and operation costs took place, as well as the formulation of the respective cost functions. All the costs were reported in the year 2005. The following simplifications were considered:

- the investment cost did not include the project cost, the building permit and the taxes;

- the operation cost did not include the extraction and deposition of sludge from the Imohff tank or from the septic tank.

The formulation of cost functions of energy-saving wastewater treatment systems consisted in the assessment of the relationship between the dependent variables $Y 1(Y 1=$ investment cost/served population) and $Y 2$ ( $Y 2=$ operation cost/served population) and the independent variable $X$ ( $X=$ served population) by regression analysis, using the models following described, with a level of significance of $5 \%$ :

- Inverse $Y=a+b_{1} / X$

- Logarithmic $Y=a+b_{1} \ln X$

- Power $Y=a X^{b_{1}}$

- Quadratic $Y=a+b_{1} X+b_{2} X^{2}$

$a, b_{1}$ and $b_{2}$ being the parameters of the model to estimate.

The adjustment's quality was evaluated not only by the determination coefficient $\left(R^{2}\right)$ but also through residues analysis. This analysis allowed the determination of extreme observations that had a high level of residues and showed themselves of great relevance. This analysis consisted in a study of the residues' distribution, to check if they presented an approximately normal distribution. The statistical software SPSS 14.0 for Windows was used for regression analysis. 


\section{Results and discussion}

Economic assessment of energy-saving systems

The inventory complied with the purpose of clarifying the investment and operation costs energy-saving wastewater treatment systems for small communities (lower than 250 p.e.), under DEPURANAT project, is translated in the Table 1.

A first analysis of the results presented in Table 1 shows that the equipment cost represents, in general, a small percentage (5\%) of the investment cost of energy-saving treatment systems. This result is attributed to the limited use of mechanical and electromechanical equipments (e.g. pump and flowmeter).

The investment costs ( $€ /$ p.e.) and annual operation costs ( $€ /$ p.e. $)$, depicted in Figures 2 and 3, respectively, present a decreasing tendency with the increase of the population served by the treatment systems. Ingenio de Santa Lúcia and Lomo Fregenal investment costs do not follow this tendency being considerably higher than the ones presented by the other treatment systems for a similar size of population served. This result is explained by the number of constructed wetlands, two in the case of Lomo Fregenal and three in the case of Ingenio de Santa Lúcia, which contributed to the increased costs. The different energy-saving wastewater treatment systems serving small population communities, between 50 p.e. and 250 p.e., present associated investment costs varying from $400 € /$ p.e. to $200 € /$ p.e.

The treatment systems of Laurisilva and Campus de Tafira, two free-water-surface constructed wetlands, present annual operation costs considerably lower than the rest of the systems, which vary between $70 € /$ p.e. and $20 € /$ p.e., for a similar size of population served. The treatment system of Laurisilva, integrated into a natural park, and Campus de Tafira, integrated into an University Campus, are operated by personal affect to the park and to the university, respectively, which explain the reduced operation costs, when compared with the other systems.

In the scope of this study several types of energy-saving wastewater treatment systems are included, occurring, nevertheless, a predominance of the type constructed wetland. The investment cost associated with this specific type of system was determined considering treatment systems with only one constructed wetland and excluding the costs of land acquisition, preliminary and primary treatment and the land fence. In this situation, the investment costs $(€ /$ p.e.), depicted in Figure 4, show a decreasing tendency with the increase of the population served, varying between $250 € /$ p.e. and the $150 € /$ p.e. for a served population between the 20 p.e. and the 60 p.e.

Literature references point to investment costs of constructed wetlands, in the Andalusia region (Spain), between $400 € /$ p.e. and $250 € /$ p.e., for a served population in the range of 150 p.e. to 250 p.e. (Sallas, 2004). Seyring and Kuschk (2005) compared the investment costs in constructed wetlands in two countries: In Germany, for a served population less than 2000 p.e., the investment costs lay in an interval between $1500 € /$ p.e. and $150 € /$ p.e., while in Mexico for the same served population the investment costs vary between $400 € /$ h.e. e $150 € /$ h.e. In this context, it can state that the investment costs obtained in the scope of DEPURANAT project are closer to the ones obtained in the region of Andalusia (Spain) and Mexico, very likely due to the low cost of the manual labor in these places. It is important to stress that the investment cost still depends, on other factors - in particular on the material resistance during excavations, which is very case specific.

The investment costs in constructed wetlands result from several items, as depicted in Figure 5, representing both the land proofing and the support medium around 56\% of total cost investment, in the case of horizontal-flow. In comparison, the vertical-flow constructed wetland systems have higher costs with piping; the costs of proofing, support medium and piping amount to around $70 \%$ of total investment cost. The results of the 
Table 1 Investment and operation costs of energy-saving wastewater treatment systems implemented or upgrade under DEPURANAT project

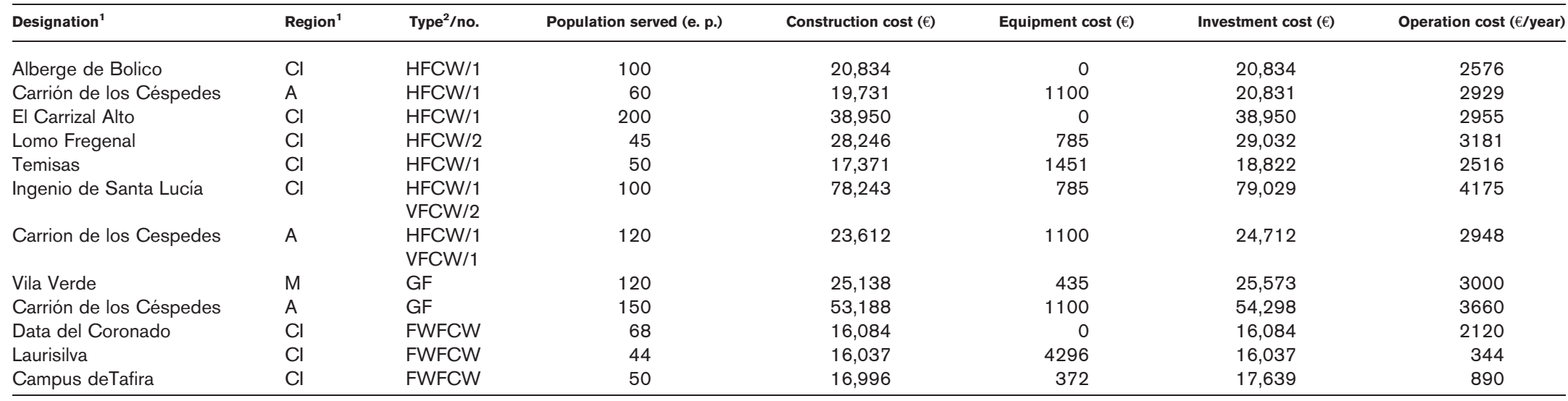

${ }^{1} \mathrm{~A}$ - Andalusia (Spain), Cl - Canaries islands (Spain), M - Minho (Portugal)

${ }^{2}$ GF - Slow rate infiltration; HFCW - Horizontal-flow constructed wetland; VFCW - Vertical-flow constructed wetland; FWFCW - Free-water-surface constructed wetland 


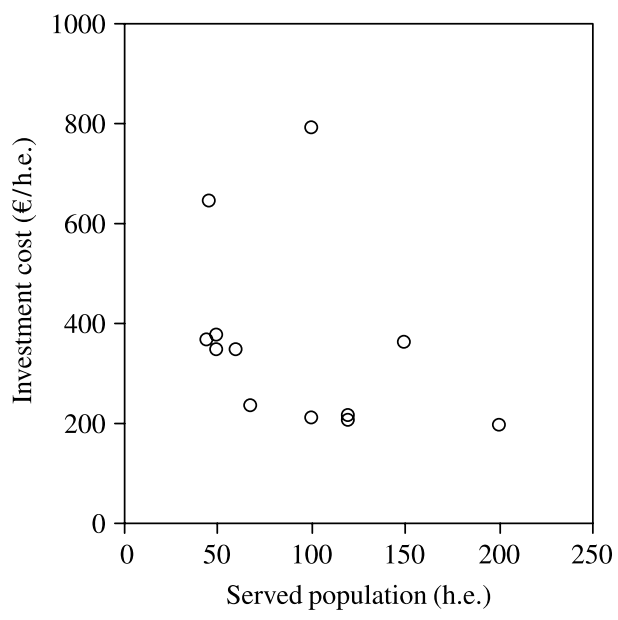

Figure 2 Investment cost as a function of served population

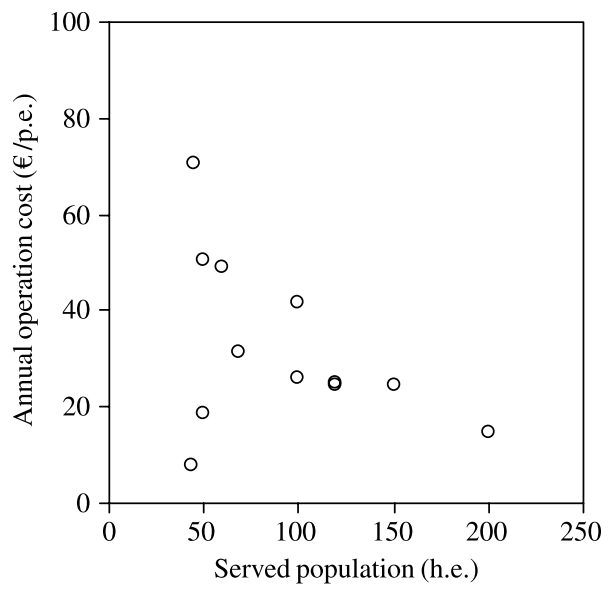

Figure 3 Operation cost as a function of served population

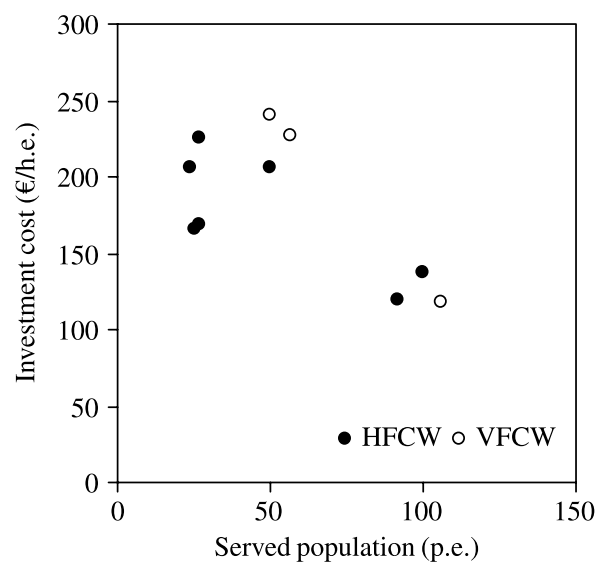


A

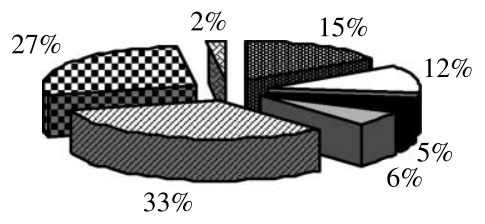

娄 Land excavation
$\square$ Containment
Flow distribution boxes
$\square$ Tubes/accessories
B

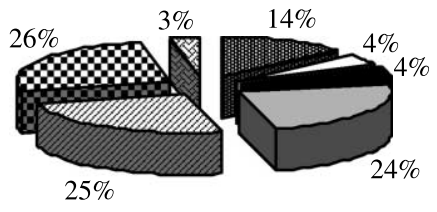

■ Proofing

๑ Support medium

Biomass

Figure 5 Distribution of costs associated with Constructed wetlands: A) horizontal-flow; B) vertical-flow

Though current study is focused on costs associated to energy-saving wastewater treatment technologies it is considered adequate to establish a comparison with the intensive technologies (Table 2). Studies performed in Spain and France show that the investment costs of energy-saving systems are in general, lower than ones for the intensive systems. The exploitation of different energy-saving systems is, certainly, less expensive than the operation of the intensive systems, in particular concerning the energy cost but, also, the cost of sludge management.

\section{Formulation of cost functions}

The relation between the dependent variable $Y 1 \quad(Y 1=$ investment cost/served population) and the independent variable $X$ ( $X=$ served population), presented in Figure 2, was evaluated by regression analysis, using the mathematical models previously described, with a significance level of $5 \%$.

The coefficient of determination $\left(R^{2}\right)$ obtained for all tested models presented values lower than 0.3, indicating a low degree of association between the independent and the dependent variables. The interpretation of relevant statistical parameters from the regression analysis suggested the elimination of two data points, Ingenio de Santa Lucía (CW) and Carrión de los Céspedes (SRI), for being considerably apart of the tendency line of the others. The regression analysis of the reduced sample reveal an increase of the $R^{2}$ of all models, the power model presented the highest value (Table 3 ).

Table 2 Literature review of investment and operation costs associated with energy-saving and intensive wastewater treatment systems

\begin{tabular}{|c|c|c|c|c|c|c|}
\hline \multirow[t]{2}{*}{ France $^{1}$} & \multicolumn{3}{|c|}{ Intensive treatment systems } & \multicolumn{3}{|c|}{ Energy-saving treatment systems } \\
\hline & $\begin{array}{c}\text { Extended } \\
\text { aeration }\end{array}$ & Bio-discs & $\begin{array}{l}\text { Trickling } \\
\text { filter }\end{array}$ & Lagoon & $\begin{array}{c}\text { Slow } \\
\text { infilteration } \\
\text { rate }\end{array}$ & $\begin{array}{c}\text { Constructed } \\
\text { wetland }\end{array}$ \\
\hline Investment & 230 & 220 & 180 & 120 & 190 & 190 \\
\hline Operation & 11.5 & 7 & 7 & 4.5 & 6 & 5.5 \\
\hline Spain $^{2}$ & $\begin{array}{l}\text { Extended } \\
\text { aeration }\end{array}$ & $\begin{array}{l}\text { Biofilm } \\
\text { circulating } \\
\text { reactor }\end{array}$ & $\begin{array}{l}\text { Trickling } \\
\text { filter }\end{array}$ & $\begin{array}{l}\text { Lagoon } \\
\text { treatment } \\
\text { system }\end{array}$ & $\begin{array}{l}\text { Turf } \\
\text { filter }\end{array}$ & \\
\hline Investment & 210 & 204 & 198 & 162 & 168 & \\
\hline Operation & 22.3 & 16.8 & 15 & 7.8 & 10.8 & \\
\hline
\end{tabular}

${ }^{1}$ System for 1000 inhabitants

${ }^{2}$ System for 2000 inhabitants 
Table 3 The relation between $Y_{1}\left(Y_{1}=\right.$ investment cost/served population and $Y_{2}\left(Y_{2}=\right.$ operation cost/population served) and the independent variable $X(X=$ population served $)$

\begin{tabular}{llll}
\hline Type & \multicolumn{1}{c}{ Treatment system } & Regression equation & $\boldsymbol{R}^{\mathbf{2}}$ \\
\hline Investment & Natural $(n=10)$ & $Y_{1}=4406 \times X^{-0.628}$ & 0.72 \\
Annual operation & Natural $(n=10)$ & $Y_{2}=1663 \times X^{-0.872}$ & 0.85 \\
Investment & Constructed wetland $(n=6)$ & $Y_{1}=490 \times X^{-0.293}$ & 0.71 \\
\hline
\end{tabular}

${ }^{1}$ The costs are expressed in $€ /$ p.e. and the served population in p.e.

The same procedure was followed in the formulation of the operation cost function, which consisted in the evaluation of the relation between the dependent variable $Y 2$ ( $Y 2=$ operation cost/served population) and independent variable $X(X=$ served population). The interpretation of relevant statistical parameters from the regression analysis of the selected models suggested the elimination of two points of the sample, Laurisilva and Campus de Tafira, two free-water-surface constructed wetlands, for being considerably apart from the others tendency line. The result of the regression analysis of the reduced sample revealed an increase of $R^{2}$ value of all the models, the power model presented the highest value (Table 3 ). The investment cost function referring to horizontal horizontal-flow constructed wetlands presented in Table 3 was obtained from regression analysis of a sample which excludes the correspondent point of El Carrizal Alto.

\section{Conclusions}

The formulated investment and operation cost functions follow a power law, and the costs decrease with the increase of the served population. The development of this type of functions is very important as it allows the elaboration of simplified budgets, based on a reduced number of variables, which are easily identifiable and quantifiable, having direct implications in the investment and operation costs.

Finally, it is important to note that natural treatment systems for low population areas are, in general, constructed in rural places or in urban outskirts. The inherent characteristics of this kind of treatment, which in general does not cause noise and presents landscape value and scenical quality, contribute to reinforce its public acceptance in comparison to the intensive treatment systems.

\section{References}

Boutin, C., Duchène, P. and Liénard, A. (1997). Filières adaptées aux petites collectivités, Document technique FNDAE no 22.

Conselho da União Europeia (1991). Directiva 91/271/CEE - Tratamento de Águas Residuais Urbamas, Jornal Oficial das Comunidades Europeias L 135, Bruxelas, 30 deMaio de 1991.

Crites, R. and Tchobanoglous, G. (1998). Small and decentralized wastewater managment systems. McGrawHill Series in Water Resources and Environmental Engineering, pp. 527-699.

García, I., Rodríguez, J., Rodríguez, J., Suárez, B., Bocardo, J. and Martín, N. (2006). Guia sobre tratamientos de aguas residuales urbanas para pequeños núcleos e población, $1^{\mathrm{a}} \mathrm{ed}$, pp. 55-101.

Jensen, A.A., Hoffman, L., Møller, B.T., Schmidt, A., Christiansen, K., Elkington, J. and van Dijk, F. (1997). Life Cycle Assessment (LCA): A Guide to Approaches, Experiences and Information Sources, Report to the Environmental Agency, Environmental Issues Series, no 6. Copenhagen.

Metcalf and Eddy, Inc. (2003). Wastewater Engineering - Treatment, Disposal, and Reuse, (4th edn), McGraw-Hill, New York, pp. 2-23.

Sallas, J.J. (2004). Centro de las nuevas tecnologias del agua (CENTA). Seminar on natural wastewater treatment systems. http://depuranat.itccanarias.org/

Seyring and Kuschk (2005) Are constructed wetlands a cost-effective alternative to activated sludge systems? Investigation of plants in Germany and Mexico (2005), International Meeting on Phytodepuration, Lorca, Spain, pp. 136-141. 